\title{
Effects of age, sex, and treatment on weight-loss dynamics in overweight people
}

Miguel A. Rojo-Tirado, Pedro J. Benito, David Atienza, Emiliano Rincón, and Francisco J. Calderón; on behalf of the PRONAF Study Group

\begin{abstract}
The objective of this work was to evaluate how sex, age, and the kind of treatment followed affect weight loss in overweight men and women, as well as to develop an explanation for the evolution of weight-loss dynamics. The study consisted of 119 overweight participants (18-50 years old, body mass index $>25$ and $<29.9 \mathrm{~kg} \cdot \mathrm{m}^{-2}$ ), who were randomly assigned to 1 of 4 treatment programs, namely, strength training $(n=30)$, endurance training $(n=30)$, a combination of strength training and endurance training $(n=30)$, and a careful treatment including diet and physical recommendations $(n=29)$. Each of the training groups exercised 3 times per week for 24 weeks, and their daily diet was restricted to a specific protocol during the testing period and controlled carefully. Body weight changes in the participants were evaluated every 15 days. Based on this study, we developed and validated different sets of equations to accurately capture the weight-loss dynamics. There were no significant differences in terms of global body weight changes from the statistical viewpoint, either regarding the carried out treatment or the individuals' ages. However, significant differences in weight-loss tendency were found depending on participant sex. We concluded that the effectiveness of different possible treatments for weight loss varies by sex and, based on our experimental observations, a quadratic function provides the most accurate model for capturing specific weight-loss dynamics. This trial is registered at Clinical Trials Gov.: number NCT01116856.
\end{abstract}

Key words: body weight, caloric restriction, exercise intervention, functions, weight-loss dynamics.

Résumé : Cette étude évalue la manière par laquelle le sexe, l'âge et le type de traitement suivi influencent la perte de poids et propose une thèse sur l'évolution de la dynamique de la perte de poids chez des femmes et des hommes présentant un surpoids. Cent dix-neuf sujets âgés de 18 à 50 ans et présentant un indice de masse corporelle entre 25 et $29,9 \mathrm{~kg} \cdot \mathrm{m}^{-2}$ sont répartis aléatoirement dans l'un des quatre groupes suivants : entraînement à la force $(n=30)$, entraînement en endurance $(n=30)$, entraînement à la force et en endurance $(n=30)$ et traitement particulier incluant des recommandations sur les plans alimentaire et kinésique $(n=29)$. Tous les groupes d'entraînement effectuent leurs exercices trois fois par semaine durant vingt-quatre semaines; en outre, l'apport alimentaire journalier est contrôlé soigneusement et limité à un protocole spécifique au cours de la période expérimentale. Par la suite, on évalue tous les quinze jours la variation du poids corporel des participants. À la lumière de ces données, on a élaboré et validé diverses équations de la dynamique de perte de poids. D'un point de vue statistique, on n'observe aucune différence significative des variations globales du poids d'un traitement à l'autre et d'un groupe d'âge à l'autre. En contrepartie, on observe une différence de tendance au sujet de la perte de poids selon le sexe. L'efficacité de divers traitements à des fins de perte de poids varie selon le sexe et, d'après nos observations, une équation quadratique procure le meilleur modèle de prédiction de la dynamique de la perte de poids. Numéro RCGT : NCT01116856. [Traduit par la rédaction]

Mots-clés : poids corporel, restriction calorique, intervention kinésique, fonctions, dynamique de la perte de poids.

\section{Introduction}

Forty to sixty percent of adults in the western world are actively attempting to reduce their body weight (BW). Nevertheless, overweight and obesity remain 2 highly predominant sources of health problems, suggesting that many options exist to improve the training programs and methods currently used for weight loss (Bendixen et al. 2002; Bish et al. 2005; Serdula et al. 1999).

Several studies have analyzed the factors that may influence weight loss and BW maintenance, and it has been determined that a reduced diet is a prerequisite in any weight-loss program (Ballor et al. 1988; Del Corral et al. 2009; Kraemer et al. 1997; Raatz et al. 2008). Moreover, these studies have indicated that possible weight loss is greater if exercise is included in the overall weight-loss program (Brochu et al. 2009; Ghroubi et al. 2009; Hagan et al. 1986). More precisely, some of these studies have described different weight-loss tendencies with different treatments (Brochu et al.
2009; Del Corral et al. 2009; Larson-Meyer et al. 2010), whereas others have analyzed how variables such as sex (Hagan et al. 1986), psychosocial actions (Jakicic et al. 2008), and lifestyle control (Redman et al. 2007; Volpe et al. 2008) affect weight loss. However, to the best of our knowledge, no study to date has focused on the overall effect of the combined interaction of all these variables on weight-loss tendencies.

In the usual approaches to weight loss, weight is lost very rapidly in the first phase of the program, and the greatest peak in loss occurs precisely 6 months after beginning treatment; however, the weight is regained slowly and usually returns to its initial level (Jeffery et al. 2000; Svetkey et al. 2008). Typically, 30\%-35\% of the lost weight is regained within a year after treatment (Wadden et al. 2004). Approximately $20 \%$ of individuals can be considered as successfully maintaining the results of a weight-loss program, which is defined as losing (at least) $10 \%$ of one's weight and maintaining that loss for a minimum of 1 year (Wing and Hill 2001).

Received 14 November 2012. Accepted 9 April 2013.

M.A. Rojo-Tirado, P.J. Benito, and F.J. Calderón. Department of Health and Human Performance, Faculty of Physical Activity and Sport Sciences, Technical University of Madrid, Madrid, Spain.

D. Atienza and E. Rincón. Embedded Systems Laboratory, École Polytechnique Fédérale de Lausanne, Lausanne, Switzerland.

Corresponding author: Miguel Ángel Rojo-Tirado (e-mail: ma.rojo@upm.es). 


\section{Pagination not final/Pagination non finale}

Table 1. Baseline data $(n=84)$

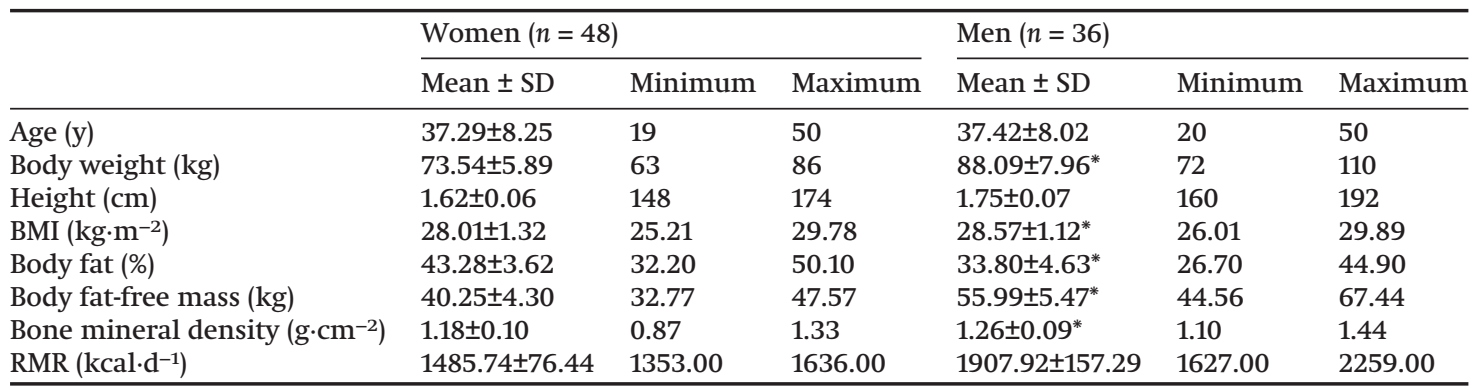

Note: BMI, body mass index; RMR, resting metabolic rate.

*Significantly different from women, $p<0.05$.

This weight-loss trend has been analyzed in the literature (Hagan et al. 1986; Jakicic et al. 2008; Kraemer et al. 1997; Redman et al. 2007; Volpe et al. 2008), and various studies have proposed mathematical models for weight-loss tendencies, based on BW or body composition changes (Hall et al. 2011, 2012; Thomas et al. 2009). However, none of these existing studies have been able to develop a specific trend line or validate any equation by analyzing variations related to age, sex, or treatment.

Therefore, research is needed to determine a mathematical function that correctly represents weight-loss dynamics and, even more important, to determine how this function behaves depending on the sex and age of the individual, as well as the treatment followed. The purpose of this work was to evaluate the effects of these variables on weight-loss tendencies and to analyze how they can be captured by a general function that represents weight-loss dynamics. This function should enable predictions to be made about future BW losses and help determine the most appropriate treatment for each person.

\section{Materials and methods}

A recent paper published by Zapico et al. (2012) provides a detailed description of the type of methodology used in this work. Therefore, in this section, we describe this initial methodology as it was adapted for this study.

\section{Participants}

The characteristics of the participants are summarized in Table 1 . All the subjects were healthy, with an overweight condition (i.e., a body mass index (BMI) between 25 and $29.9 \mathrm{~kg} \cdot \mathrm{m}^{-2}$ ); they were nonsmokers, sedentary (i.e., $\leq 2 \mathrm{~h}$ of exercise per week) (Brochu et al. 2009), and had normal fasting glycemia (Rutter et al. 2012). The female participants had regular menstrual cycles.

All the participants were recruited through advertisement campaigns covering a wide variety of media (television, radio, press, and Internet). The final sample set consisted of 46 middle-aged males (aged 18-50 years) and 73 females, who were all living in the Madrid region of Spain. Because of drop-out, there were 84 participants at the end of the intervention period, and 51 of those answered an online questionnaire about lifestyle and BW evolution 6 months after the intervention (Fig. 1). The participants were classified by age and sex and were divided randomly into a strength-training group (S), an endurance-training group (E), a combined strength- and endurance-training group (SE), and a diet and physical recommendations group (C). An institutionally approved consent document was signed by each individual before the start of the intervention, in agreement with the guidelines of the Declaration of Helsinki regarding research on human subjects. In addition, the project was approved by the Human Research Review Committee of La Paz University Hospital (PI-643).

\section{Experimental design}

Body composition was assessed through dual-energy X-ray absorptiometry (DXA). Resting maximal heart and 15 repetition maximum (15RM) rates were measured before and after the 16-week intervention, and BW was evaluated every 15 days. All the subjects were instructed to continue their usual daily activities from the period right before the intervention period, and accelerometer devices were provided to monitor their physical activity during a full week each month. Then, 6 months after the end of the intervention, all the subjects who completed the study were required to provide their lifestyle information and BW on a Web questionnaire. We used this information to further analyze their respective weight-loss tendencies; no follow-up on their exercise patterns or food intake was performed during these months.

\section{Intervention}

Diet

Diet prescriptions were given to all participants by dietitians at the Endocrinology Department of La Paz University Hospital. Each participant followed an individualized hypocaloric diet, with a $25 \%-30 \%$ caloric restriction (CR) from their own daily energy expenditure (DEE) (National Institutes of Health 1998), which was measured by using the SenseWear Pro Armband. Macronutrient distribution was performed according to Spanish Society of Community Nutrition recommendations (Dapcich et al. 2004). The dietitians reviewed each 3-day food record and interviewed each participant on a regular basis, both 3 months after the start of the intervention and at the end of the intervention period. The interviews consisted of face-to-face consultation sessions (30-60 min), during which the subjects received input about food portion sizes and diet variations. In addition, voluntary group sessions and expert lectures provided the subjects with the knowledge and skills to gradually achieve more consistent (eventually permanent) behavioral habits.

\section{Training}

All the training groups followed a personalized training program, which consisted of exercise sessions 3 times per week for a period of 6 months, supervised carefully by qualified personal trainers. The first 4 weeks were used for training adaptation, and maximal heart rate (HR) during the exercise sessions within that period was determined according to the Bruce protocol. Next, strength was assessed twice on different days during the evaluation period, using the 15RM testing method described for $S$ and SE (Morgan et al. 2003). In addition, HR reserve (HRR) was calculated by using Karvonen's equation (Earle and Baechle 2004), to prescribe exercise intensity for those participants following the $\mathrm{E}$ and SE intervention programs. During the intervention period, $S$ and SE feedback about training loads was obtained once a month through the rate of perceived exertion scale, to evaluate each session by each person in a subjective way. Thus, it was possible to determine the intensity level that each participant was considered to have reached. This process was carried out by following a methodology similar to the one proposed by Shaibi et al. (2006). 


\section{Pagination not final/Pagination non finale}

Rojo-Tirado et al.

Fig. 1. Participant flow diagram. S, strength-training group; E, endurance-training group; SE, combined strength- and endurance-training group; $\mathrm{C}$, diet and physical recommendations group.

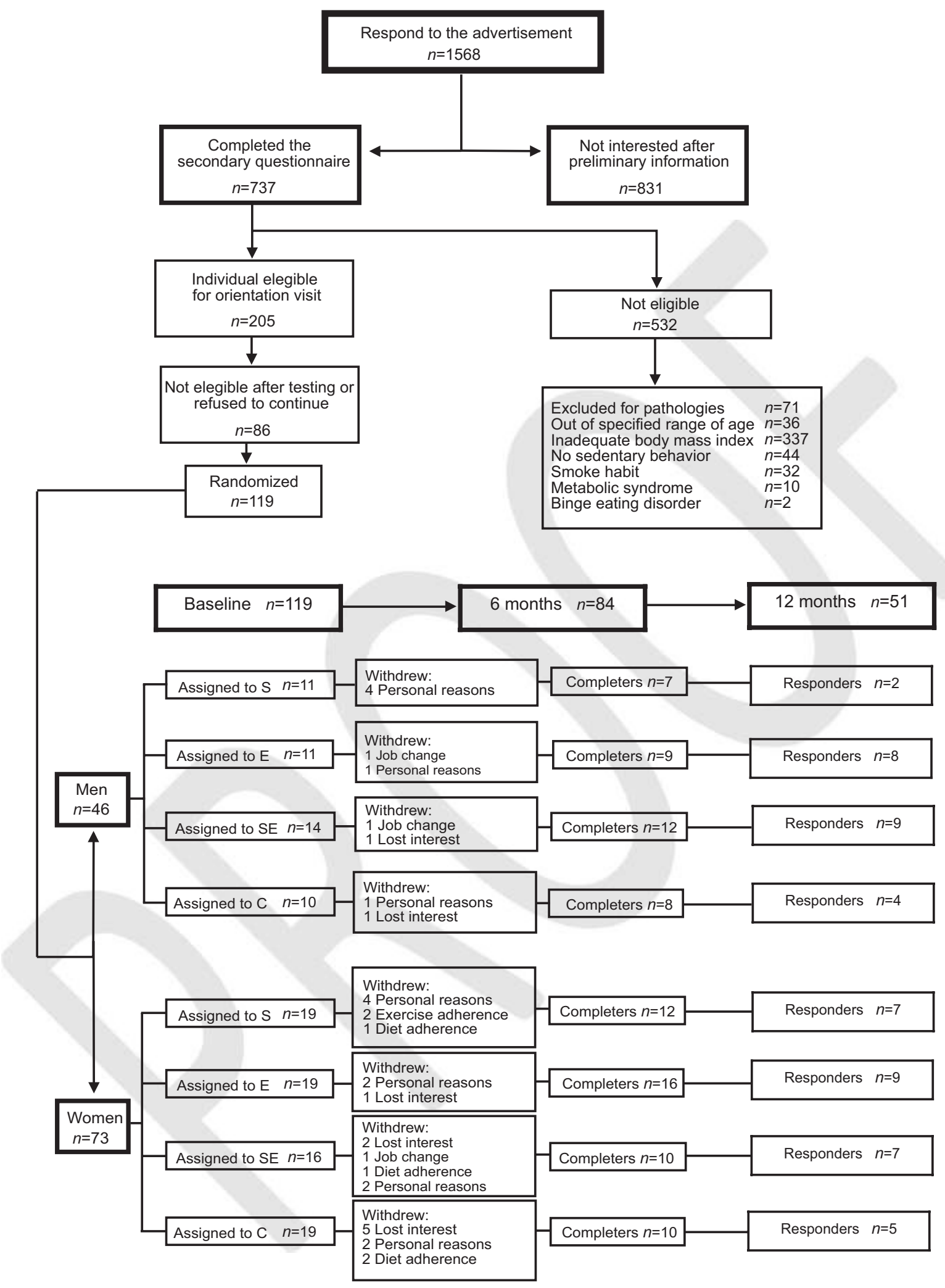

Each training session (in the S, E, and SE groups) started with a 5-min aerobic warm-up routine followed by the session routine and then a 5-min cool-down and stretching exercise. An MP3 audio track was played for each participant to set the execution rhythm of the exercises during all the sessions. HR was monitored by a pulse-meter (Polar RS800CX, Polar Electro, Kempele, Finland). The cadence for the resistance exercises was fixed at 1:2 (concentric-eccentric phase). In the case of $S$, a session routine 
consisted of 8 scheduled exercises (i.e., shoulder press, squat, barbell row, lateral split, bench press, front split, biceps curl, and French press for triceps). For E, running, cycling, or elliptical (selfselected) exercises were the main components of the session routine, whereas the routine for SE consisted of a combination of cycle ergometry, treadmill, or elliptical intercalated with squat, row machine, bench press, and front split. Finally, the participants in $\mathrm{C}$ followed the dietary intervention and the physical activity recommendations of the American College of Sports Medicine (Donnelly et al. 2009).

The volume and intensity of the 3 training programs increased progressively. During the adaptation period (i.e., weeks 1-4), the subjects were taught the different exercise routines. During weeks 5 to 8 , the exercises were carried out at an intensity of $50 \%$ of 15RM and HRR, and the subjects performed 2 laps of the circuit (51 min and $15 \mathrm{~s}$ in total). During weeks 9 to 14 , the intensity was increased to $60 \%$ of $15 \mathrm{RM}$ and HRR. Finally, during weeks 15 to 24 , the volume was increased to 3 circuit laps instead of 2 (64 min in total). In addition, 5-min recovery periods were established between the circuit laps. The $S$ and SE participants performed 15 repetitions (45") for each exercise, including a rest period of $15 \mathrm{~s}$ between repetitions.

\section{Experimental assessments}

All the tests were standardized and were conducted by the same test team before and after the intervention. Furthermore, all assessments, data collection, and previous training sessions were carried out using the same devices and the same free-weight volumes (Johnson Health Tech, Iberica, Matrix, Spain).

\section{Body weight}

BW was measured in kilograms every 15 days, with a scale precision in the range of $100 \mathrm{~g}$. The participants who were receiving both diet and physical recommendations used their own scales to monitor their BW at home, except for the initial and final measurements. On the contrary, BW follow-up for the individuals in the training groups was performed at the gym with a Tanita scale (TANITA BC-420MA, Bio Lógica, TecnologíaMédica SL).

\section{Body composition}

Anthropometric measurements included height (stadiometer SECA, range 80-200 cm) and BW (TANITA BC-420MA). The samples characterization was assessed by DXA (GE Lunar Prodigy, GE Healthcare, Madison, Wis., USA), and scan analysis was performed using GE Encore 2002 software (version 6.10.029), measuring the total body fat (\%), body fat-free mass (FFM) (kilograms), and bone mineral density (grams.centimetre ${ }^{-2}$ ).

\section{Resting metabolic rate}

The subjects were asked to refrain from doing any exercise for at least a period of $24 \mathrm{~h}$ before the test. To assess the resting metabolic rate (RMR), the participants were cited between $7 \mathrm{~h}$ to $10 \mathrm{~h}$, after a 9-h overnight fasted period. The RMR was then measured standing up (for $11 \mathrm{~min}$ ) and in a lying-down position (for an additional $20 \mathrm{~min}$ ) by indirect calorimetry. Oxygen consumption $\left(\mathrm{VO}_{2}\right)$ and carbon dioxide production $\left(\mathrm{VCO}_{2}\right)$ were recorded by a gas analyzer (Jaeger Oxycon Pro, Erich Jaeger, Viasys Healthcare, Germany), and resting HR was measured using an HR monitor (Polar RS800CX). All these parameters were averaged during the last $5 \mathrm{~min}$ of the standing-up position and the last $10 \mathrm{~min}$ of the lying-down position. Finally, $\dot{\mathrm{V}} \mathrm{O}_{2}$ and $\dot{\mathrm{V}} \mathrm{CO}_{2}$ data were used to calculate the RMR figures according to the formula proposed by Weir (1949).

\section{Physical activity and DEE}

Physical activity was assessed once a month, as described in the previous section, by using a SenseWear Pro3 Armband (Body Media, Pittsburgh, Pa., USA). The subjects were instructed to wear the monitoring system continuously for 5 days, including both weekends and weekdays, while following the general recommendations proposed by Murphy et al. (2009). Data were recorded in 15-min intervals. Finally, DEE was calculated using the body media propriety algorithm (Interview Research Software, version 6.0).

\section{Energy balance, adherence to diet, and exercise}

All the subjects were instructed to continue their typical daily activity sequence during the intervention period. At the beginning of the intervention, negative energy balance was calculated, taking into account the DEE and a 3-day food record, to accurately decrease the energy intake by $25 \%-30 \%$ during the intervention period. Energy intake was calculated every 3 months through a 3-day food record, including 2 weekdays and 1 weekend day. The subjects were instructed to accurately record the weights of food consumed whenever possible; otherwise, they were requested to use typical home-related object measurements (spoonfuls, cups, etc.). The energy and nutritional content of the food consumed was calculated subsequently using DIAL software (Alce Ingeniería 2004). Finally, to determine diet compliancy, the obtained values were compared with the recommended dietary intakes for the Spanish population (Ortega et al. 2004). The subjects were required to report the kind, duration, and intensity of any physical activity, as well as the amount of any food intake, during the intervention period by recording everything in a notebook on a daily basis.

Adherence to diet recommendations was calculated as the estimated kilocalories of the diet divided by the real kilocalorie intake, as a percentage ((estimated kilocalories of diet/real kilocalorie intake) $\times 100$ ), $100 \%$ being the greatest adherence. Adherence to exercise was calculated as the number of completed sessions with respect to the theoretical sessions ((sessions performed/total sessions) $\times 100$ ). Greater than $90 \%$ adherence to the training sessions and greater than $80 \%$ adherence to the diet were required.

\section{Determination coefficients of the functions to assess weight-loss dynamics}

The BW values obtained every 15 days were used to derive the functions to assess the dynamics of weight loss by applying different types of regression methods. In particular, 5 different regression equations (linear, power law, exponential, logarithmic, and quadratic) were calculated, and the best coefficients were obtained and compared.

\section{Statistical analyses}

The data were analyzed statistically using PASW Statistics, version 18.0 for Windows (SPSS Inc., Chicago, Ill., USA). Data are presented as means $\pm \mathrm{SD}$. A multivariate analysis of variance (ANOVA) (MANOVA) was employed to analyze the baseline measures by sex, age, and treatment. Next, an analysis of covariance (ANCOVA) with repeated measures was used to compare the initial and final BW by sex, age, and group, with diet and exercise adherence as covariates. A 3-way ANOVA with repeated measures (in the sixth and 12th month) was used to compare the $R^{2}$ of the functions of the weight loss dynamics by sex and type of equation. Finally, a 2-way ANOVA with repeated measures (before and after the 6-month intervention) was used to compare the FFM and the RMR changes by treatment. In addition, multiple evaluations were made with the Bonferroni post hoc test. Finally, we considered values of $p$ below 0.05 to be statistically significant.

\section{Results}

\section{Baseline characteristics}

The characteristics of the 84 individuals who completed the intervention are shown in Fig. 1. MANOVA revealed differences according to sex in BW (kilocalories) $\left(\mathrm{F}_{[1,62]}=79.071, p<0.001\right)$, BMI $\left(F_{[1,62]}=10.148, p=0.002\right)$, body fat $(\%)\left(F_{[1,62]}=79.031, p<0.001\right)$, body FFM $\left(F_{[1,62]}=189.548, p<0.001\right)$, bone mineral density $\left(F_{[1,62]}=\right.$ 14.436, $p<0.001)$, and $\operatorname{RMR}\left(F_{[1,62]}=259.379, p<0.001\right)$ at baseline. 


\section{Pagination not final/Pagination non finale}

Table 2. Changes in body weight by age, sex, and type of treatment.

\begin{tabular}{|c|c|c|c|c|c|c|c|c|c|}
\hline \multirow[b]{2}{*}{ Group } & \multirow[b]{2}{*}{ Age (y) } & \multicolumn{4}{|c|}{ Women } & \multicolumn{4}{|l|}{ Men } \\
\hline & & No. & $\begin{array}{l}\text { Initial } \\
\text { BW (kg) }\end{array}$ & $\begin{array}{l}\text { Final } \\
\text { BW (kg) }\end{array}$ & $\%$ & No. & $\begin{array}{l}\text { Initial } \\
\text { BW (kg) }\end{array}$ & $\begin{array}{l}\text { Final } \\
\text { BW (kg) }\end{array}$ & $\%$ \\
\hline$S$ & $18-30$ & 3 & $72.7 \pm 7.4$ & $67.9^{*} \pm 7.1$ & -6.52 & 1 & $76.0 \pm 0.0$ & $73.0 \pm 0.0$ & -3.95 \\
\hline Women $(n=12)$ & $31-40$ & 4 & $77.0 \pm 7.4$ & $70.7^{*} \pm 7.6$ & -8.18 & 2 & $90.5^{\dagger} \pm 7.8$ & $86.3^{\dagger} \pm 7.4$ & -4.70 \\
\hline $\operatorname{Men}(n=7)$ & $41-50$ & 5 & $73.0 \pm 4.1$ & $67.6^{*} \pm 5.5$ & -7.45 & 4 & $92.8^{\dagger} \pm 7.8$ & $85.8^{*}, \dagger \pm 10.5$ & -7.49 \\
\hline Total & & 12 & $74.3 \pm 5.9$ & $68.7 \pm 6.2$ & -7.48 & 7 & $89.7 \pm 8.9$ & $84.1 \pm 9.4$ & -6.25 \\
\hline $\mathrm{E}$ & $18-30$ & 2 & $69.0 \pm 2.8$ & $68.6 \pm 6.6$ & -0.65 & 2 & $84.0^{\dagger} \pm 2.8$ & $70.1^{*} \pm 3.1$ & -16.55 \\
\hline Women $(n=16)$ & $31-40$ & 7 & $74.6 \pm 7.5$ & $70.7^{*} \pm 8.5$ & -5.29 & 3 & $89.9^{\dagger} \pm 7.2$ & $84.4^{*, \dagger} \pm 9.3$ & -6.09 \\
\hline Men $(n=9)$ & $41-50$ & 7 & $74.2 \pm 4.0$ & $66.4^{*} \pm 7.5$ & -10.49 & 4 & $92.3^{\dagger} \pm 13.4$ & $83.1^{*}+\dagger \pm 12.0$ & -9.97 \\
\hline Total & & 16 & $73.7 \pm 5.7$ & $68.6 \pm 7.6$ & -7.04 & 9 & $89.6 \pm 9.6$ & $80.6 \pm 10.6$ & -10.04 \\
\hline SE & $18-30$ & 2 & $64.0 \pm 1.4$ & $57.0 * \pm 3.4$ & -10.94 & 1 & $102.0^{\dagger} \pm 0.0$ & $93.5^{*}+\dagger \pm 0.0$ & -8.33 \\
\hline Women $(n=10)$ & $31-40$ & 3 & $74.7 \pm 10.7$ & $67.6^{*} \pm 10.5$ & -9.43 & 6 & $83.8 \pm 9.0$ & $74.0^{*} \pm 9.8$ & -11.64 \\
\hline $\operatorname{Men}(n=12)$ & $41-50$ & 5 & $71.6 \pm 6.7$ & $64.4^{*} \pm 7.8$ & -10.00 & 5 & $86.1^{\dagger} \pm 4.5$ & $77.0^{*, \dagger} \pm 1.9$ & -10.52 \\
\hline Total & & 10 & $71.0 \pm 7.8$ & $63.9 \pm 8.3$ & -9.99 & 12 & $86.3 \pm 8.4$ & $76.9 \pm 8.7$ & -10.85 \\
\hline C & $18-30$ & 3 & $74.8 \pm 2.0$ & $68.8^{*} \pm 9.4$ & -8.10 & 2 & $95.0^{\dagger} \pm 0.0$ & $91.5^{\dagger} \pm 2.3$ & -3.68 \\
\hline Women $(n=10)$ & $31-40$ & 3 & $77.5 \pm 3.5$ & $70.2^{*} \pm 2.4$ & -9.42 & 4 & $87.1 \pm 3.6$ & $78.2^{*} \pm 6.5$ & -10.22 \\
\hline Men $(n=8)$ & $41-50$ & 4 & $73.0 \pm 4.4$ & $66.8^{*} \pm 4.7$ & -8.52 & 2 & $83.7 \pm 8.9$ & $75.9^{*} \pm 13.5$ & -9.38 \\
\hline Total & & 10 & $74.6 \pm 3.6$ & $68.2 \pm 5.8$ & -8.59 & 8 & $88.2 \pm 6.0$ & $80.9 \pm 9.4$ & -8.25 \\
\hline Total & $18-30$ & 10 & $70.9 \pm 5.6$ & $66.1 \pm 7.8$ & -6.68 & 6 & $89.3 \pm 9.7$ & $81.6 \pm 11.8$ & -8.63 \\
\hline Women $(n=48)$ & $31-40$ & 17 & $75.6 \pm 7.1$ & $70.0 \pm 7.5$ & -7.33 & 15 & $86.8 \pm 7.2$ & $78.8 \pm 9.2$ & -9.15 \\
\hline Men $(n=36)$ & $41-50$ & 21 & $73.1 \pm 4.6$ & $66.3 \pm 6.3$ & -9.28 & 15 & $89.2 \pm 8.8$ & $80.8 \pm 9.3$ & -9.38 \\
\hline Total & & 48 & $73.5 \pm 5.9$ & $67.5^{*} \pm 7.1$ & -8.07 & 36 & $88.2^{\dagger} \pm 8.1$ & $80.1^{*, \dagger} \pm 9.4$ & -9.16 \\
\hline
\end{tabular}

Note: Data are presented as means \pm SD (adjusting for diet and exercise adherences). BW, body weight; S, strength-training group;

E, endurance-training group; SE, combined strength- and endurance-training group; C, diet and physical recommendations group.

*Significantly different from pre, $p<0.05$.

†Significantly different from women, $p<0.05$.

All these values were higher for the men than for the women, except for body fat (\%). Finally, no differences were found in these baseline variables by taking age range and treatment into account $(p>0.05)$.

\section{FFM, RMR, and DEE}

After the intervention period, FFM decreased only in C $(-0.913 \pm$ $1.635 \mathrm{~kg}, p<0.05)$; it remained unaltered in S, E, and SE $(0.189 \pm$ $0.874,-0.376 \pm 1.249$, and $0.023 \pm 1.618$, respectively; $p>0.05$ ). The RMR was significantly decreased in all groups (S: $-62.94 \pm$ $52.93 \mathrm{kcal}$; E: $-78.54 \pm 58.8 \mathrm{kcal}$; SE: $-104.35 \pm 44.75 \mathrm{kcal}$; and C: $-79.53 \pm 62.57 \mathrm{kcal} ; p<0.001)$. The DEE decreased significantly in $S$ and SE $(-200.971 \pm 290.36 \mathrm{kcal}$, and $-24.895 \pm 386.14 \mathrm{kcal}$, respectively; $p<0.005)$ and increased in $\mathrm{E}(117.474 \pm 389.51 \mathrm{kcal}$, $p=0.001)$, whereas it remained unchanged in C $(-217.427 \pm$ $474.212 \mathrm{kcal}, p>0.05)$. No differences were found in FFM, RMR, or DEE among the different treatments, either initially or finally $(p>0.05)$. The RMR decreased consistently in both sexes (women: $-56.904 \pm 36.645$ and men: $-111.22 \pm 60.79 ; p<0.001)$. However, the DEE decreased in the women $(-101.79 \pm 326.8, p<0.001)$ but remained the same in the men $(-6.409 \pm 487.26, p=0.399)$.

\section{BW loss}

The results related to BW remained unaltered when the analyses were adjusted for diet and exercise adherences covariates. The only differences between the sexes $\left(F_{[1,59]}=66.742, p<0.001\right)$ were found in BW loss, which cannot be shown clearly when weight loss is compared with percentage change from baseline. The observed statistical power for these comparisons was 0.999. No differences were found regarding age $\left(F_{[2,59]}=0.412, p>0.05\right)$ or type of treatment $\left(\mathrm{F}_{[3,59]}=0.258, p>0.05\right)$. Table 2 shows BW (in kilograms) in the 4 groups before and after the intervention period, differentiated by sex, age range, and type of treatment. Within each treatment group, there were no differences among the different age ranges, either initially or finally $(p>0.05)$. Similarly, within each age range, no significant differences were found among the different treatments, either initially or finally. These results should be interpreted with caution because the number of subjects in each subgroup was not sufficient to perform a more thorough statistical analysis.

After the intervention period, the women aged 41 to 50 years reduced their BW by $7.45 \%$ in $S$, by $10.49 \%$ in $\mathrm{E}$, by $10 \%$ in $\mathrm{SE}$, and by $8.52 \%$ in $C(p<0.05)$. The women aged 31 to 40 years reduced their BW by $8.18 \%$ in S, by $5.29 \%$ in E, by $9.43 \%$ in SE, and by $9.42 \%$ in C $(p<0.05)$. However, those female subjects aged 18 to 30 years reduced their BW only by $6.52 \%$ in S, by $10.94 \%$ in SE, and by $8.1 \%$ in $C(p<0.05)$. In the case of the men, those participants aged 41 to 50 years reduced their BW by $7.49 \%$ in S, by $9.97 \%$ in E, by $10.52 \%$ in SE, and by $9.38 \%$ in $C(p<0.05)$. BW was also reduced for the men aged 31 to 40 years following the E, SE, and C treatments (by $6.09 \%$, $11.64 \%$, and $10.22 \%$, respectively; $p<0.05$ ). For those participants aged 18 to 30 years, BW was reduced only in the case of treatments E and SE (by $16.55 \%$ and $8.33 \%$, respectively; $p<0.05$ ).

\section{Functions of weight-loss dynamics}

Table 3 shows the extracted coefficients $\left(R^{2}\right)$ used to apply a T3 linear, power law, exponential, logarithmic, and quadratic fit to the BW changes, according to sex. For this analysis, the sample set consisted of the 51 subjects who completed the online form 6 months after the end of the intervention. When the $R^{2}$ values were compared, significant differences were found between the sexes $\left(F_{[1,243]}=12.686, p<0.001\right)$ and among the types of function $\left(F_{[4,243]}=11.271, p<0.001\right)$. The observed statistical powers for these comparisons were 0.944 and 0.999 , respectively. Figures 2 and 3 F2-F3 represent the 5 types of functions analyzed in both sexes at months 6 and 12 .

At 6 months, no differences between the women and the men $(p>0.05)$ were revealed among the different equations. In both cases, it is shown that the quadratic function has the highest coefficient $(0.893 \pm 0.16$ for the women and $0.948 \pm 0.051$ for the men) and the power law function has the lowest $(0.779 \pm 0.209$ for the women and $0.878 \pm 0.09$ for the men). The men have the higher $R^{2}$ in the 5 functions; it is significantly higher in the power law $(0.878 \pm 0.09)$ and logarithmic $(0.882 \pm 0.089)$ functions than is the women's $R^{2}(0.779 \pm 0.209$ and $0.784 \pm 0.211$, respectively) $(p<0.05)$. At 12 months, the $R^{2}$ value is decreased in all functions 
Table 3. $R^{2}$ of the linear, power law, exponential, logarithmic, and quadratic equations from the body weight evolution by sex $(n=51)$.

\begin{tabular}{|c|c|c|c|c|}
\hline \multirow[b]{2}{*}{ Equation } & \multicolumn{2}{|l|}{ Women } & \multicolumn{2}{|l|}{ Men } \\
\hline & $6 \mathrm{mo}$ & $12 \mathrm{mo}$ & $6 \mathrm{mo}$ & $12 \mathrm{mo}$ \\
\hline Linear & $0.830 \pm 0.244$ & $0.502^{*} \pm 0.275$ & $0.887 \pm 0.103$ & $0.575^{*} \pm 0.228$ \\
\hline Power law & $0.779 \pm 0.209$ & $0.678^{*}, a \pm 0.258$ & $0.878^{\dagger} \pm 0.090$ & $0.796^{*, a} \pm 0.175$ \\
\hline Exponential & $0.833 \pm 0.246$ & $0.520^{*} \pm 0.271$ & $0.890 \pm 0.104$ & $0.583^{*, b} \pm 0.231$ \\
\hline Logarithmic & $0.784 \pm 0.211$ & $0.683^{*}, a \pm 0.259$ & $0.882^{\dagger} \pm 0.089$ & $0.800^{*}, a, c \pm 0.176$ \\
\hline Quadratic & $0.893 \pm 0.160$ & $0.864^{a, b, c, d} \pm 0.204$ & $0.948 \pm 0.051$ & $0.927^{a, c} \pm 0.064$ \\
\hline
\end{tabular}

Note: Data are presented as means \pm SD.

*Significantly different from 6 months, $p<0.05$.

†Significantly different from women, $p<0.05$.

${ }^{a}$ Significantly different from linear equation, $p<0.05$.

bSignificantly different from power law equation, $p<0.05$.

cSignificantly different from exponential equation, $p<0.05$.

aSignificantly different from logarithmic equation, $p<.005$.

for both sexes compared with the $R^{2}$ at 6 months $(p<0.05)$, except in the quadratic function, in which it remains higher $(0.864 \pm$ 0.204 for the women and $0.927 \pm 0.064$ for the men). In this case, the men's $R^{2}$ values are not significantly different from those of the women. In the women, the quadratic function has the highest $R^{2}$ value, and it is different from the other 4 functions $(p<0.05)$. In the men, the $R^{2}$ for the quadratic function is the highest as well, but it is not significantly different from all the other models. The quadratic function for the men is shown to be differentiated clearly from the linear $(0.575 \pm 0.228)$ and the exponential $(0.583 \pm$ 0.231) fitting functions.

\section{Discussion}

The main purpose of this study was to evaluate the effects of the variables sex, age, and treatment on weight loss and how they affect the function that represents these dynamics. This study showed that BW loss is affected mainly by sex, because age and treatment did not appear to influence BW loss, and that the function that best fits the BW loss dynamics for both sexes is the quadratic function.

Abdominal fat loss could have been used as an appropriate metric because of its higher rates of pathogenesis; however, from a practical point of view, a study of the dynamics of weight loss is more interesting to health professionals, because weight loss is the main concern for people following any weight-loss program. We analyzed the BW loss in kilograms, because it is the easiest measurement that a person can obtain every 15 days (only a scale is necessary). Other measurements, such as body fat (\%), require more complex equipment, and a large spectrum of measurement possibilities exists (e.g., anthropometric, BIA, DXA, etc.). Even though a possible limitation was that we did not assess the DXA value more frequently, we believe it was not necessary to perform a DXA every 15 days because it is an expensive method and, moreover, it is not recommended for humans because of its high frequency exposure. During the exercise intervention, any weight loss would have been a loss of fat mass because it has been demonstrated that exercise preserves lean tissue during any period of significant weight loss (Janssen et al. 2002; Janssen and Ross 1999; Rice et al. 1999). Hence, it was enough to measure BW to conclude that the person had a new water balance or a decrease in fat mass (\%), although water rebalancing tends to occur in the early stages of exercise. In fact, this situation was observed in this study, because the training groups conserved FFM.

In addition, our diet and physical recommendations group was not completely sedentary. This group carried out some exercise according to physical activity recommendations, as happens in real life when a person begins a weight-loss program, but it appears that these recommendations were not sufficient to maintain the FFM. Therefore, when regulated exercise is not included in a weight-loss program, as in C, part of the BW loss is due to the loss of FFM. For this reason, although weight loss was significant in this group (except for the men aged 18-30 years), we advocate including physical exercise to maintain FFM in any weight-loss program, which would contribute to maintaining the body's overall energy expenditure rate (Ravussin et al. 1986) and has significant cardiometabolic health benefits (Larson-Meyer et al. 2010). However, because exercise cannot guarantee a $25 \%$ caloric use constraint by itself (i.e., it requires approximately $120 \mathrm{~min}$ for women and $90 \mathrm{~min}$ for men, which is very difficult to guarantee with the busy professional lives today (Redman et al. 2007)), we recommend a combination of diet and exercise.

\section{BW loss}

As explained previously, to achieve weight loss in any program, it is necessary to generate a negative energy balance, mainly by a restrictive diet because a significant decrease in BW cannot be achieved with exercise alone (Villareal et al. 2011). In this study, it was generated by the $25 \%-30 \%$ CR that was combined with the training protocols in some groups. To analyze the weight loss, we took into account the 6-month intervention period. There was a significant reduction in BW in both sexes, according to the results obtained by Hagan et al. (1986) and Redman et al. (2007) in the CALERIE Study. As people age, there is a loss of FFM and a decrease in RMR (Kraemer et al. 1997; Pavlou et al. 1986; Redman et al. 2007). This can produce a smaller weight loss in middle-aged than in younger people. Nevertheless, it does not occur when the intervention is controlled and supervised (Ghroubi et al. 2009) and the diet is individually adapted to the DEE estimated by accelerometry, as in this study. Our results do not show differences in weight loss among the types of treatment. A growing body of literature supports this finding, indicating that exercise, in combination with dietary restriction, leads to similar reductions in BW (Brochu et al. 2009; Crncevć-Orlić et al. 2008; Deibert et al. 2007; Larson-Meyer et al. 2010; Redman et al. 2007). Similar BW changes were obtained in other 6-month interventions with overweight populations. In those cases, BW was reduced by approximately 10\% (Crncevć-Orlić et al. 2008; Jakicic et al. 2008; Larson-Meyer et al. 2010; Redman et al. 2007, 2009). Hagan and Kraemer showed a reduction in BW of around 10\% in a 3-month intervention, which differed from previous findings. Hagan's results can be explained

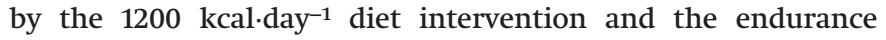
exercise treatment, which took place 5 days $\cdot$ week $^{-1}$ instead of 3 days. week $^{-1}$, and Kraemer's results can be explained by the exercise intensity, which was from $70 \%$ to $80 \%$ of functional capacity for the endurance exercise and 5 to 10 repetition maximum for the strength exercise (Kraemer et al. 1997). Moreover, Del Corral et al. (2009) obtained greater BW reductions (about 15.6\%) with $800 \mathrm{kcal} \cdot \mathrm{day}^{-1}$ meals provided twice a week. When interventions are conducted in a clinic (Del Corral et al. 2009), greater results are obtained. However, our results are closer to real life, because each 
Pagination not final/Pagination non finale

Rojo-Tirado et al.

Fig. 2. Functions and $R^{2}$ of the dynamics of weight loss in women. Data are presented as means and SE.

Women

6 months

12 months
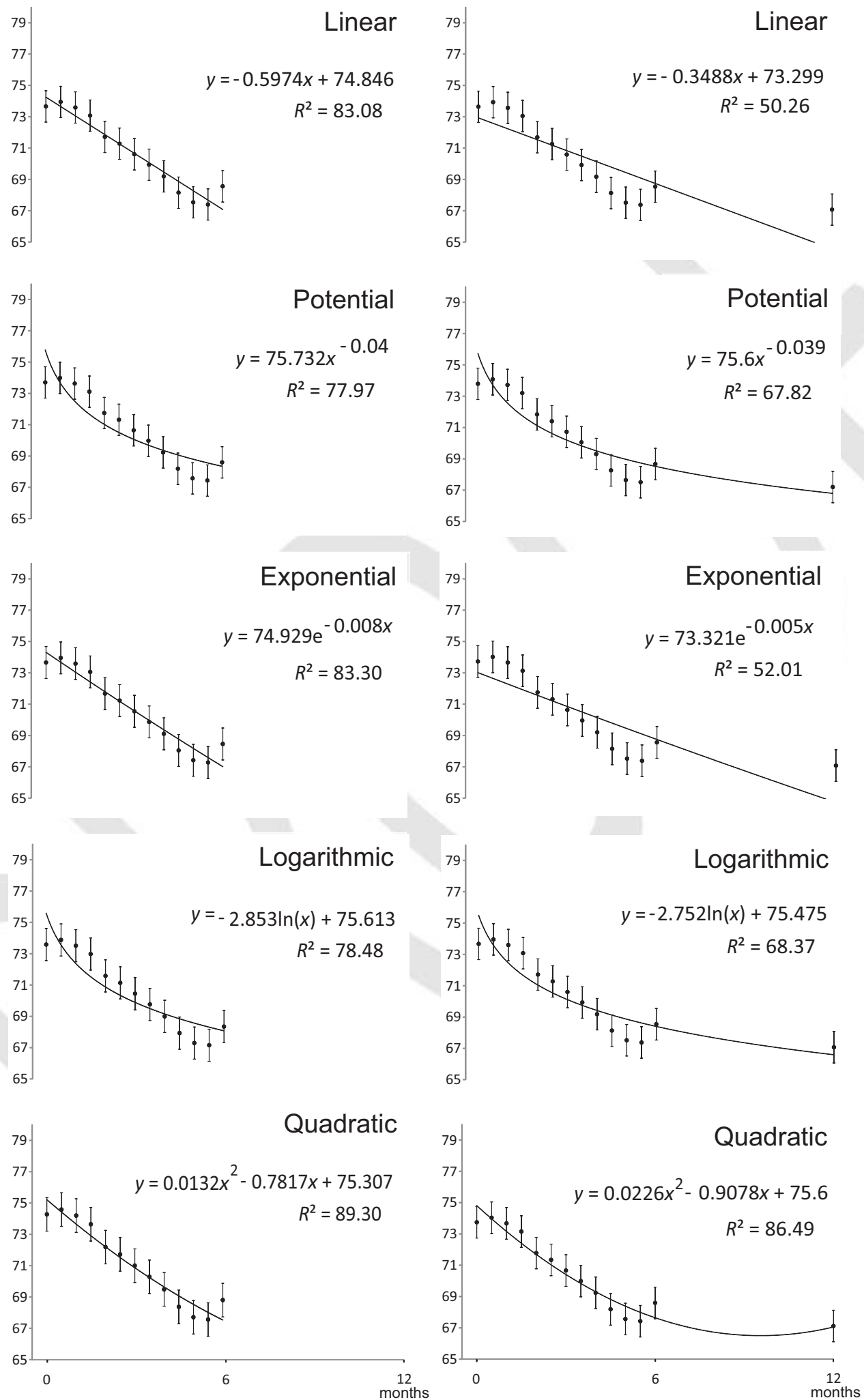
Fig. 3. Functions and $R^{2}$ of the dynamics of weight loss in men. Data are presented as means and SE.

\section{Men}

6 months 12 months
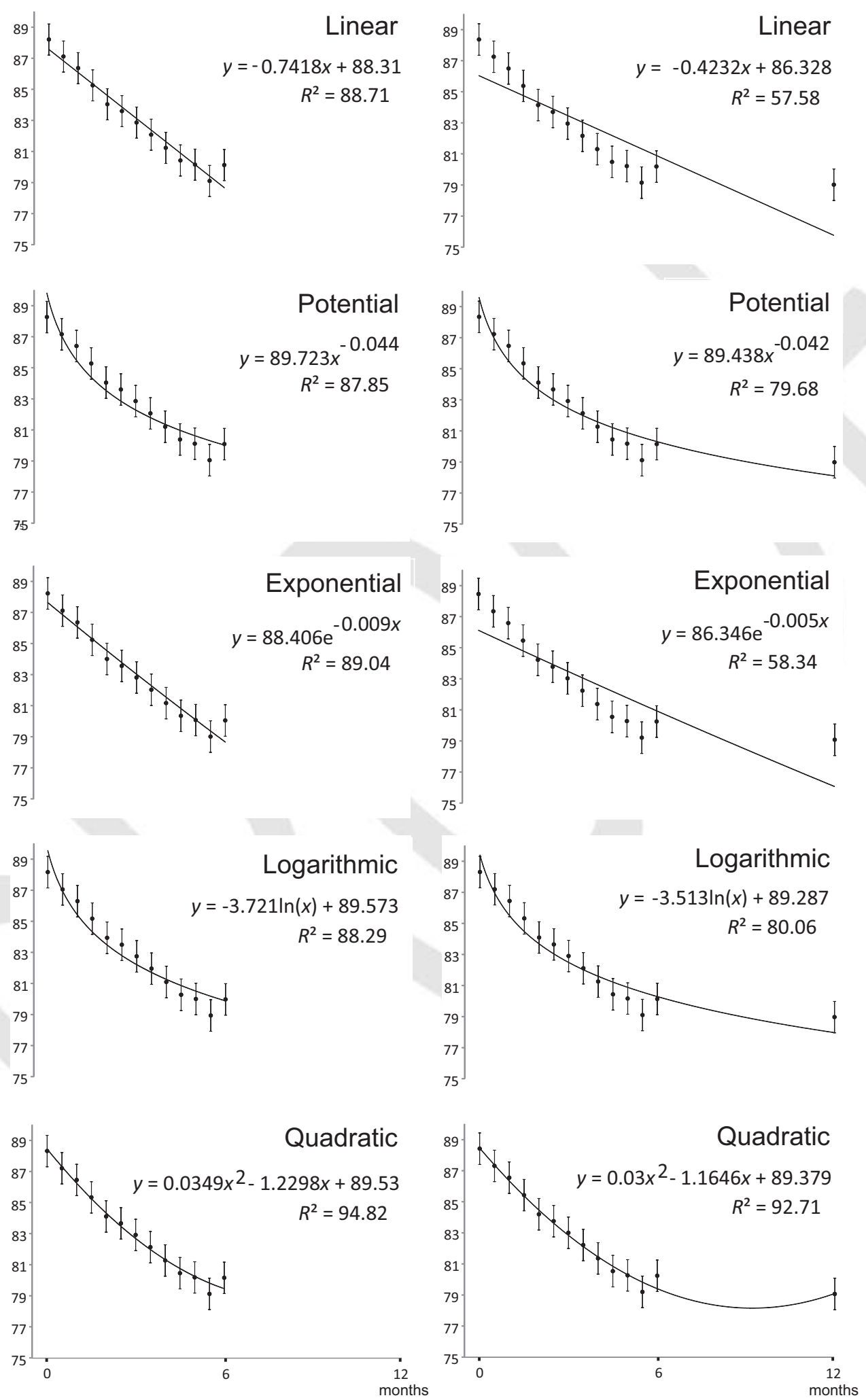
participant prepared his or her own meals at home, which leads to a long-lasting acquisition of healthy habits. Figures 2 and 3 show how the weight loss was maintained for at least 6 months.

\section{Functions of weight-loss dynamics}

In our study, the BW loss in the 6-month program matches a quadratic function well. Furthermore, these results are similar beyond 6 months of weight maintenance. Our study was based on monitoring the BW evolution during the intervention, as well as when the intervention ended (i.e., when the participants returned to a completely autonomous lifestyle). The 6-month intervention may have been a limitation of this study because it has been shown in previous studies that weight is regained over a longer term. Jakicic et al. (2008) showed that in an intervention similar to ours, after a similar weight loss at 6 months, BW increased progressively to 24 months. The decrease in physical activity after month 6 and the lack of compliance with dietary recommendations may have contributed to regaining the BW (Jakicic et al. 2008). In the future, it would be interesting to use a longer intervention period and to determine the different factors that influence the dynamics of weight loss.

The expected further weight reduction (or even maintaining the weight loss) may have been difficult to achieve after the intervention period because of hormonal factors (Hagobian et al. 2009), a decline in DEE, genetics characteristics (Bray 2008), a decline in adherence to diet (Acharya et al. 2009; Svetkey et al. 2008), an energy intake substantially higher than reported by the subjects (Heymsfield et al. 2007, Lichtman et al. 1992), or a metabolic adaptation (MA) (Heilbronn et al. 2006; Martin et al. 2007). In fact, MA occurs when the body adapts to CR by decreasing RMR. This adaptation occurred in our sample, because the RMR was decreased in the sixth month for all treatments, even in the training groups that maintained FFM. This MA was also observed in CR clinical studies with durations of between 3 and 8 months, in which RMR decreased by approximately $6 \%$, which supports our result of a decrease of 4.8\% (Apfelbaum et al. 1971; Bray 1969; Heilbronn et al. 2006). There appears to be considerable variance in how much MA inhibits individual weight loss (Heilbronn et al. 2006; Martin et al. 2007). For example, Pavlou et al. (1986) reported that even without kilojoule restriction, obese individuals are characterized by a suppressed RMR when compared with individuals of normal BW and body composition. Redman et al. (2009) showed that the total DEE was lower during weight loss with $25 \% \mathrm{CR}$ and tended to be lower during weight-loss maintenance. Brochu et al. (2009) and Hunter et al. (2008) showed this decreased RMR in a 6-month intervention. However, the strength trainers group from Hunter's study did not decrease the RMR that led to maintenance of RMR following a return to energy balance, as this group trained at $65 \%-80 \%$ of the 1 repetition maximum, an intensity higher than ours. This means that, to maintain RMR and avoid MA, exercise intensity should be high in any weight-loss program based on CR. This "physiological adaptation" is postulated to be an integral factor in protecting against excessive weight loss during CR and, importantly, predisposing to weight regain in postobese individuals (Leibel et al. 1995). In other studies, a 10\% weight loss in lean subjects resulted in a $10 \%-15 \%$ lower energy requirement for weight maintenance. These adaptations in the metabolic rate may be explained by an improved metabolic efficiency of the skeletal muscle or, as also postulated, by a reduction in physical activity with weight loss, because the energy cost of physical activity is proportional to BW (Hall 2010; Leibel et al. 1995; Rosenbaum et al. 1996, 2003). An interesting phenomenon also observed in different CR studies is the change in nonexercise activity thermogenesis (NEAT). The impact of NEAT on resistance to change in body mass has been the focus of several studies, which found that physical activity levels decreased over 3 months of CR (Hirsch 2003; Leibel et al. 1995; Levine et al. 1999; Martin et al. 2007; Sims 1976). In short, a combination of all these factors may contribute to a reduction in the usual course of weight-loss dynamics, even to an increase in BW after the 6-month intervention period, as has been demonstrated previously (Jeffery et al. 2000), thus describing the BW loss as a quadratic function.

\section{Conclusions}

In conclusion, in this study of weight-loss programs with $25 \%-$ $30 \%$ of CR, BW was significantly decreased in both sexes, regardless of age and type of treatment followed. According to the results of this study, the weight loss achieved by an individual (male or female) during a 6-month intervention period similar to the one developed in this work can be represented by any of the 5 functions (linear, power law, exponential, logarithmic, and quadratic), but the quadratic fitting achieves the best results. Moreover, after 6 months of the intervention period, the best representation of the weight evolution is shown by the quadratic function formulation for both women and men. Future research is needed to determine if this conclusion and the developed models can be extrapolated to other weight-loss programs.

\section{Conflict of interest}

The authors do not have any conflict of interest.

\section{Acknowledgements}

The PRONAF Study is made possible with the financial support of the Ministerio de Ciencia e Innovación, Convocatoria de Ayudas I + D 2008, Proyectos de Investigación Fundamental No Orientada, del VI Plan de Investigación Nacional 2008-2011, (Contract: DEP2008-06354-C04-01). This work was also funded partially by the Nano-Tera.ch ObeSense RTD project (ref. 20NA21_143081), which is financed by the Swiss Confederation and is scientifically evaluated by the SNSF. The authors do not have any conflicts of interest to declare.

\section{References}

Acharya, S.D., Elci, O.U., Sereika, S.M., Music, E., Styn, M.A., Turk, M.W., et al. 2009. Adherence to a behavioral weight loss treatment program enhances weight loss and improvements in biomarkers. Patient Prefer Adherence, 3: 151-160. doi: 10.2147/PPA.S5802. PMID:19936157.

Apfelbaum, M., Bostsarron, J., and Lacatis, D. 1971. Effect of caloric restriction and excessive caloric intake on energy expenditure. Am. J. Clin. Nutr. 24: 1405-1409. PMID:5118011.

Ballor, D.L., Katch, V.L., Becque, M.D., and Marks, C.R. 1988. Resistance weight training during caloric restriction enhances lean body weight maintenance. Am. J. Clin. Nutr. 47: 19-25. PMID:3337037.

Bendixen, H., Madsen, J., Bay-Hansen, D., Boesen, U., Ovesen, L.F., Bartels, E.M., and Astrup, A. 2002. An observational study of slimming behavior in Denmark in 1992 and 1998. Obes. Res. 10: 911-922. doi:10.1038/oby.2002.125. PMID:12226140.

Bish, C.L., Blanck, H.M., Serdula, M.K., Marcus, M., Kohl, H.W., and Khan, L.K. 2005. Diet and physical activity behaviors among Americans trying to lose weight: 2000 Behavioral Risk Factor Surveillance System. Obes. Res. 13: 596607. doi:10.1038/oby.2005.64. PMID:15833946.

Bray, G. 1969. Effect of caloric restriction on energy expenditure in obese patients. Lancet, 2: 397-398. PMID:4184486.

Bray, M.S. 2008. Implications of gene-behavior interactions: prevention and intervention for obesity. Obesity (Silver Spring), 16 (S3): S72-S78. doi:10.1038/ oby.2008.522.

Brochu, M., Malita, M.F., Messier, V., Doucet, E., Strychar, I., Lavoie, J.M., et al. 2009. Resistance training does not contribute to improving the metabolic profile after a 6-month weight loss program in overweight and obese postmenopausal women. J. Clin. Endocrinol. Metab. 94(9): 3226-3233. doi:10.1210/ jc.2008-2706. PMID:19567540.

Crncevć-Orlić, Z., Jovanović, Z., Stimać, D., Zaputović, L., Persić, V., and Ruzić, A. 2008. Efficacy of healthy weight loss program in obesity treatment: Croatian experience. Coll. Antropol. 32(1): 79-84. PMID:18494192.

Dapcich, V., Salvador Castell, G., Rivas Barba, L., Pérez Rodrigo, C., Aranceta Bartrina, J., and Serra Majem, L. 2004. Guía de la alimentación saludable. SENC.

Deibert, P., König, D., Vitolins, M.Z., Landmann, U., Frey, I., Zahradnik, H.P., et al. 2007. Effect of a weight loss intervention on anthropometric measures and metabolic risk factors in pre- versus postmenopausal women. Nutr. J. 6: 31. doi:10.1186/1475-2891-6-31. PMID:17961235.

Del Corral, P., Chandler-Laney, P.C., Casazza, K., Gower, B.A., and Hunter, G.R. 2009. Effect of dietary adherence with or without exercise on weight loss: a 
mechanistic approach to a global problem. J. Clin. Endocrinol. Metab. 94(5): 1602-1607. doi:10.1210/jc.2008-1057. PMID:19258409.

Donnelly, J.E., Blair, S.N., Jakicic, J.M., Manore, M.M., Rankin, J.W., and Smith, B.K. 2009. American College of Sports Medicine Position Stand. Appropriate physical activity intervention strategies for weight loss and prevention of weight regain for adults. Med. Sci. Sports. Exerc. 41(2): 459-471. doi: 10.1249/MSS.0b013e3181949333.

Earle, R., and Baechle, T. 2004. NSCA's essentials of personal training. Human Kinetics, Champaign, Ill., USA.

Ghroubi, S., Elleuch, H., Chikh, T., Kaffel, N., Abid, M., and Elleuch, M.H. 2009. Physical training combined with dietary measures in the treatment of adult obesity. A comparison of two protocols. Ann. Phys. Rehabil. Med. 52(5): 394413. doi:10.1016/j.rehab.2008.12.017.

Hagan, R.D., Upton, S.J., Wong, L.E.S., and Whittam, J. 1986. The effects of aerobic conditioning and/or caloric restriction in overweight men and women. Med. Sci. Sports Exerc. 18(1): 87-94. PMID:3457234.

Hagobian, T.A., Sharoff, C.G., Stephens, B.R., Wade, G.N., Silva, J.E., Chipkin, S.R., et al. 2009. Effects of exercise on energy-regulating hormones and appetite in men and women. Am. J. Physiol. Regul. Integr. Comp. Physiol. 296(2): R233-R242. doi: 10.1152/ajpregu.90671.2008. PMID:19073905.

Hall, K. 2010. Predicting metabolic adaptation, body weight change, and energy intake in humans. Am. J. Physiol. Endocrinol. Metab. 298: E449-E466. doi: 10.1152/ajpendo.00559.2009. PMID:19934407.

Hall, K., Sacks, G., Chandramohan, D., Chow, C., Wang, C., Gortmaker, S., et al. 2011. Quantification of the effect of energy imbalance on bodyweight. Lancet, 378: 826-837. doi:10.1016/S0140-6736(11)60812-X. PMID:21872751.

Hall, K., Heymsfield, S., Kemnitz, J., Klein, S., Schoeller, D., and Speakman, J. 2012. Energy balance and its components: implications for body weight regulation. Am. J. Clin. Nutr. 95: 989-994. doi:10.3945/ajcn.112.036350. PMID: 22434603.

Heilbronn, L.K., de Jonge, L., Frisard, M.I., DeLany, J.P., Meyer, D.E.L., Rood, J., et al. 2006. Effect of 6-mo. calorie restriction on biomarkers of longevity, metabolic adaptation and oxidative stress in overweight subjects. JAMA, 295(13): 1539-1548. doi:10.1001/jama.295.13.1539.

Heymsfield, S.B., Harp, J.B., Reitman, M.L., Beetsch, J.W., Schoeller, D.A., Erondu, N., et al. 2007. Why do obese patients not lose more weight when treated with low-calorie diets? A mechanistic perspective. Am. J. Clin. Nutr. 85: 346-354. PMID:17284728.

Hirsch, J. 2003. Obesity: matter over mind? Cerebrum: The Dana Forum on Brain Science, 5(1): 7-18.

Hunter, G.R., Byrne, N.M., Sirikul, B., Fernández, J.R., Zuckerman, P.A., Darnell, B.E., et al. 2008. Resistance training conserves fat-free mass and resting energy expenditure following weight loss. Obesity (Silver Spring), 16(5): 1045-1051. doi:10.1038/oby.2008.38.

Jakicic, J.M., Marcus, B.H., Lang, W., and Janney, C. 2008. Effect of exercise on 24-month weight loss maintenance in overweight women. Arch Intern Med, 168(14): 1550-1559. (Discussion pp. 1559-1560.) doi:10.1001/archinte.168.14. 1550. PMID:18663167.

Janssen, I., and Ross, R. 1999. Effects of sex on the change in visceral, subcutaneous adipose tissue and skeletal muscle in response to weight loss. Int. J. Obes. Relat. Metab. Disord. 23: 1035-1046. doi:10.1038/sj.ijo.0801038. PMID: 10557024.

Janssen, I., Fortier, A., Hudson, R., and Ross, R. 2002. Effects of an energyrestrictive diet with or without exercise on abdominal fat, intermuscular fat, and metabolic risk factors in obese women. Diabetes Care, 25: 431-438. doi:10.2337/diacare.25.3.431. PMID:11874926.

Jeffery, R.W., Drewnowski, A., Epstein, L.H., Wilson, G.T., Stunkard, A.J., and Wing, R.R. 2000. Long-term maintenance of weight loss: current status. Health Psychol. 19(Suppl. 1): 5-16.

Kraemer, W.J., Volek, J.S., Clark, K.L., Gordon, S.E., Incledon, T., Puhl, S.N., et al. 1997. Physiological adaptations to a weight-loss dietary regimen and exercise programs in women. J. Appl. Physiol. 83: 270-279. PMID:9216973.

Larson-Meyer, D.E., Redman, L., Heilbronn, L.K., Martin, C.K., and Ravussin, E. 2010. Caloric restriction with or without exercise: the fitness vs. fatness debate. Med. Sci. Sports Exerc. 42(1): 152-159. doi:10.1249/MSS.0b013e3181ad7f17.

Leibel, R., Rosenbaum, M., and Hirsch, J. 1995. Changes in energy expenditure resulting from altered body weight in man. N. Engl. J. Med. 332: 621-628. doi:10.1056/NEJM199503093321001. PMID:7632212.

Levine, J., Eberhardt, N., and Jensen, M. 1999. Role of nonexercise activity thermogenesis in resistance to fat gain in humans. Science, 283(5399): R212-R214. PMID:9880251.

Lichtman, S., Pisarska, K., Raynes, E., Pestone, M., Dowling, H., Offenbacher, E., et al. 1992. Discrepancy between self-reported and actual caloric intake and exercise in obese subjects. N. Engl. J. Med. 327(27): 1893-1898. doi:10.1056/ NEJM199212313272701. PMID:1454084.

Martin, C., Heilbronn, L., de Jonge, L., DeLany, J., Volaufova, J., Anton, S., et al. 2007. Effect of calorie restriction on resting metabolic rate and spontaneous physical activity. Obesity, 15(12): 2964-2973. doi:10.1038/oby.2007.354.

Morgan, B., Woodruff, S.J., and Tiidus, P.M. 2003. [Online.] Aerobic energy ex- penditure during recreational weight training in females and males. J. Sports Sci. Med. 2: 117-122.

Murphy, S.L. 2009. Review of physical activity measurement using accelerometers in older adults: considerations for research design and conduct. Prev. Med. 48(2): 108-114. doi:10.1016/j.ypmed.2008.12.001. PMID:19111780.

National Institutes of Health. 1998. Clinical guidelines on identification, evaluation, and treatment of overweight and obesity in adults. National Institutes of Health Publication, 98-4083.

Ortega, R., Requejo, A., Navia, B., and López-Sobaler, A. 2004. Recommended daily intakes of energy and nutrients for the Spanish population food composition: a basic tool for assessing nutritional status. RM, Madrid. pp. 82-85.

Pavlou, K.N., Hoefer, M.A., and Blackburn, G.L. 1986. Resting energy expenditure in moderate obesity. Predicting velocity of weight loss. Ann. Surg. 203(2): 136-141. doi:10.1097/00000658-198602000-00005. PMID:3947152.

Raatz, S.K., Wimmer, J.K., Kwong, C.A., and Sibley, S.D. 2008. Intensive diet instruction by registered dietitians improves weight-loss success. J. Am. Diet. Assoc. 108(1): 110-113. doi:10.1016/j.jada.2007.10.010. PMID:18155995.

Ravussin, E., Lillioja, S., Anderson, T., Christin, L., and Bogardus, C. 1986. Determinants of 24-hour energy expenditure in man. Methods and results using a respiratory chamber. J. Clin. Invest. 78: 1568-1578. doi:10.1172/JCI112749.

Redman, L.M., Heilbronn, L.K., Martin, C.K., Alfonso, A., Smith, S.R., Ravussin, E., et al. 2007. Effect of calorie restriction with or without exercise on body composition and fat distribution. J. Clin. Endocrinol. Metab. 92(3): 865-872. doi:10.1210/jc.2006-2184. PMID:17200169.

Redman, L.M., Heilbronn, L.K., Martin, C.K., de Jonge, L., Williamson, D.A., Delany, J.P., et al. 2009. Metabolic and behavioral compensations in response to caloric restriction: implications for the maintenance of weight loss. PLoS One, 4(2): e4377. doi:10.1371/journal.pone.0004377. PMID:19198647.

Rice, B., Janssen, I., Hudson, R., and Ross, R. 1999. Effects of aerobic or resistance exercise and/or diet on glucose tolerance and plasma insulin levels in obese men. Diabetes Care, 22: 684-691. doi:10.2337/diacare.22.5.684. PMID: 10332666

Rosenbaum, M., Ravussin, E., Matthews, D.E., Gilker, C., Ferraro, R., Heymsfield, S.B., et al. 1996. A comparative study of different means of assessing long-term energy expenditure in humans. Am. J. Physiol. 270: R496R504. PMID:8780213.

Rosenbaum, M., Vandenborne, K., Goldsmith, R., Simoneau, J., and Heymsfield, S. 2003. Effects of experimental weight perturbation on skeletal muscle work efficiency in human subjects. Am. J. Physiol. 285: R183-R192.

Rutter, M.K., Massaro, J.M., Hoffmann, U., O'Donnell, C.J., and Fox, C.S. 2012. Fasting glucose, obesity, and coronary artery calcification in communitybased people without diabetes. Diabetes Care, 35(9): 1944-1950. doi:10.2337| dc11-1950. PMID:22773705.

Shaibi, G.Q., Cruz, M.L., Ball, G.D., Weigensberg, M.J., Salem, G.J., Crespo, N.C., and Goran, M.I. 2006. Effects of resistance training on insulin sensitivity in overweight Latino adolescent males. Med. Sci. Sports Exerc. 38(7): 1208-1215. doi:10.1249/01.mss.0000227304.88406.0f. PMID:16826016.

Serdula, M.K., Mokdad, A.H., and Williamson, D.F. 1999. Prevalence of attempting weight loss and strategies for controlling weight. JAMA, 282: 1353-1358. doi:10.1001/jama.282.14.1353. PMID:10527182.

Sims, E. 1976. Experimental obesity, dietary-induced thermogenesis, and their clinical implications. Clin. Endocr. Metab. 5: 377-395. doi:10.1016/S0300595X(76)80027-8.

Svetkey, L., Stevens, V., Brantley, P., Appel, L.J., Hollis, J.F., Loria, C.M., et al. 2008. Comparison of strategies for sustaining weight loss: the weight loss maintenance randomized controlled trial. JAMA, 299: 1139-1148. doi:10.1001/jama. 299.10.1139. PMID:18334689.

Thomas, D., Ciesla, A., Levine, J., Stevens, J., and Martin, C. 2009. A mathematical model of weight change with adaptation. Math. Biosci. Eng. 6(4): 873-887. doi:10.3934/mbe.2009.6.873. PMID:19835433.

Villareal, D., Chode, S., Parimi, N., Sinacore, D., Hilton, T., ArmamentoVillareal, R., et al. 2011. Weight loss, exercise, or both and physical function in obese older adults. N. Engl. J. Med. 364: 1218-1229. doi:10.1056/ NEJMoa1008234. PMID:21449785.

Volpe, S.L., Kobusingye, H., Bailur, S., and Stanek, E. 2008. Effect of diet and exercise on body composition, energy intake and leptin levels in overweight women and men. J. Am. Coll. Nutr. 27(2): 195-208. PMID:18689550.

Wadden, T.A., Butryn, M.L., and Byrne, K.J. 2004. Efficacy of lifestyle modification for long-term weight control. Obes. Res. 12 (Suppl.): S151-S162. doi:10. 1038/oby.2004.282.

Weir, J. 1949. New methods for calculating metabolic rate with special reference to protein metabolism. J. Physiol. 109(1-2): 1-9. PMID:15394301.

Wing, R., and Hill, J. 2001. Successful weight loss maintenance. Annu. Rev. Nutr. 21: 323-341. doi:10.1146/annurev.nutr.21.1.323. PMID:11375440.

Zapico, A.G., Benito, P.J., Gonzalez-Gross, M., Peinado, A.B., Morencos, E., Romero, B., et al. 2012. Nutrition and physical activity programs for obesity treatment (PRONAF study): methodological approach of the project. BMC Public Health, 12(1): 1100. doi:10.1186/1471-2458-12-1100. 